University of Nebraska - Lincoln

DigitalCommons@University of Nebraska - Lincoln

Faculty Publications in Food Science and Technology

Food Science and Technology Department

1983

\title{
Significance of Residual Organisms in Foods after Substerilizing Doses of Gamma Radiation: A Review
}

R. B. Maxcy

University of Nebraska-Lincoln

Follow this and additional works at: https://digitalcommons.unl.edu/foodsciefacpub

Part of the Food Science Commons

Maxcy, R. B., "Significance of Residual Organisms in Foods after Substerilizing Doses of Gamma Radiation: A Review" (1983). Faculty Publications in Food Science and Technology. 57.

https://digitalcommons.unl.edu/foodsciefacpub/57

This Article is brought to you for free and open access by the Food Science and Technology Department at DigitalCommons@University of Nebraska - Lincoln. It has been accepted for inclusion in Faculty Publications in Food Science and Technology by an authorized administrator of DigitalCommons@University of Nebraska - Lincoln. 
Published in Journal of Food Safety 5:4 (1983), pp. 203-211.

Copyright (C) 1983 Food \& Nutrition Press, Inc., Westport, Connecticut;

published by John Wiley \& Sons, Inc. Used by permission.

Published as Paper No. 6960 Journal Series, Nebraska Agricultural Experiment Station.

Submitted August 13, 1982 ; accepted for publication May 19, 1983.

\title{
Significance of Residual Organisms in Foods after Substerilizing Doses of Gamma Radiation: A Review
}

\author{
R. B. Maxcy \\ Department of Food Science and Technology \\ University of Nebraska-Lincoln \\ Lincoln, Nebraska 68583
}

\begin{abstract}
The nature of the flora surviving substerilizing irradiation of foods is dependent on the dose applied and the conditions of applications as well as the microenvironment of the food. At a dose level low enough to preserve acceptable sensory properties of fresh food, few if any of the common contaminants of public health significance survive irradiation. Survivors are weakened and present no unique problem of acquired resistance through recycling. Those bacteria surviving a low dose treatment of a relatively contaminated product like ground beef can grow under normal storage conditions and cause obvious sensory spoilage. Thus, low dose irradiation extends the shelf-life of fresh foods and reduces public health hazards, but foods so treated require normal care in production and distribution.
\end{abstract}

\section{Introduction}

Irradiation like heat processing of foods may be applied in many ways and at various intensities. The specific process and food determine which, if any, organisms survive. The nature of the survivors and their significance to public health as well as their potential impact on sensory properties of the food are of paramount importance. Processing parameters must be established and knowledge of the surviving bacteria must be obtained before acceptable commercial substerilizing processes can be adopted. 


\section{Impact of Radiation}

\section{Substerilizing Irradiation of Food}

Substerilizing may be used in many ways. We should therefore consider some of the common terminology to describe the systems and indicate the levels of radiation. The lowest dose that is proposed for processing food is "radurization," which is the application of enough energy to increase the storage life of fresh food. A similar low dose process, which has the primary goal to destroy microorganisms of public health significance, is termed "radicidation." A third process is "radappertization," which is the production of a commercially sterile food.

The quantity of radiant energy applied commonly has been expressed in multiples of "rad," which is 100 ergs absorbed in one gram of food. A newer but not universally accepted unit is "gray," which is one joule absorbed in one kilogram of food. A gray is 100 times a rad. The older system is in harmony with most of the scientific literature and will be used in this report.

The quantity of radiant energy required for substerilizing processes is relative and dependent on the nature of the food and the goal to be accomplished. For example, to increase the shelflife of potatoes by retarding sprouting would be a process for radurization and would involve the application of approximately $10 \mathrm{Krad}$. A similar goal for the radurization of chicken would require approximately 200-500 Krad for the destruction of microorganisms.

Another characterization of irradiation processes is a division at the $1 \mathrm{Mrad}$ level. Lower doses are for radurization or radicidation while higher doses are for radappertization or commercial sterility. The dose level ultimately must be selected for the process that will produce the desired effect without serious ill effects on sensory properties of the specific food.

\section{Relative Resistance of Microorganisms to Radiation}

There is a comparatively great range of resistance to gamma radiation by various microorganisms of interest to the food industry. Generally, from the lowest to the highest relative resistance microorganisms can be categorized into the following groups. Pseudomonads and closely related species are most sensitive. The enteric gram-negative bacteria are nearly as sensitive. Molds and micrococci are next most resistant, and spores are still more resistant. At the extreme, there are uniquely resistant vegetative cells belonging to the pseudomonads, micrococci, and Moraxella-Acinetobacter (Welch and Maxcy 1975). The magnitude of range in comparative 
resistance may be 100 times from the most sensitive to the most resistant. The magnitude of difference in relative resistance may be accentuated by environmental conditions.

It is apparent that in a product such as meat where one might find some of all the above organisms, the nature of the surviving flora after irradiation would depend on the dose level. The effectiveness of the dose, of course, is dependent further on a number of other factors the most prominent of which are available water, oxygen, and temperature. The variability in effectiveness is similar to all other destructive forces where there is an expected variation dependent on the conditions of application.

\section{Microenvironment and Radiation Resistance}

\section{Temperature of Irradiation}

Effectiveness of gamma radiation is temperature dependent. The lower the temperature the greater the dose required to provide a given effect. For example, Bruns and Maxcy (1979) showed that approximately 5 Mrad killed the same number of Moraxella-Acinetobacter in ground beef at approximately $-30^{\circ} \mathrm{C}$ as $2 \mathrm{Mrad}$ killed at approximately $35^{\circ} \mathrm{C}$. The greatest impact of temperature change occurs at the freezing point, and is most pronounced in highly radiation-resistant vegetative cells such as Moraxella-Acinetobacter (Ma and Maxcy 1981). Spores are less affected. The marked change in effectiveness is attributable to reduction in available water through freezing (Bruns and Maxcy 1979). This is shown by the limited effect of freezing on dried cultures. Bacteria on the surface of food may react as if they are dry.

It should be pointed out that the temperature differential for flavor protection is greater than the differential for protection of bacteria. Thus, there is an advantage for irradiation in the frozen state when high doses are used.

\section{Effect of Menstruum on Survival and Recovery from the Irradiation Process}

The nature of menstruum with such factors as water availability, ionic concentration, and available oxygen influence the rate of destruction as well as recovery from radiation (Bruns and Maxcy 1978). Vacuum packaging affords some protection to bacteria. The other factors are of theoretical but limited practical interest, because variation in composition of a specific food is not great enough to pose a problem in setting dose requirements. 


\section{Evaluating Destruction by Radiation}

Nature of the Death Curve

With common, relatively sensitive microorganisms the pattern of radiation destruction is geometric like with most destructive forces. The relationship therefore can be depicted by a straight line on a semilogarithmic plot. With the highly radiation-resistant vegetative cells, however, there is a shoulder in the death curve, which indicates a lag before the onset of the geometric destruction phase (Maxcy and Rowley 1978). The shoulder accounts for a major portion of the radiation resistance and presents real challenges in evaluating a process.

The shoulder of the death curve for the highly radiation-resistant $\mathrm{Mo}$ raxella-Acinetobacter can be eliminated by a mild heat treatment applied either before or after irradiation (Maxcy and Rowley 1978). Furthermore, as a result of the heat treatment, the cells are considerably more sensitive to gamma radiation. The death rate can be depicted by a semilogarithmic plot that is a straight line and easily evaluated.

Disappearance of the shoulder of the death curve is associated with injury to the radiation-resistant bacteria, and this should be considered when evaluating survival of microorganisms in a food process. That is, bacteria that have been injured are then sensitive to other destructive or unfavorable environmental conditions. For example, progression of injury of highly radiation-resistant micrococci with increasing doses of gamma radiation was apparent on plating with plate count agar plus $1.2 \%$ salt (Tan and Maxcy 1982). These results showed a similar response to the results with Moraxella-Acinetobacter.

The injured bacteria are sensitive to similar osmolar concentrations of other solutes such as glucose (Bruns and Maxcy 1978). This equivalent concentration of dissolved substances is common in foods and a factor to be considered in evaluating the outgrowth of injured cells.

\section{Nature of Bacteria Surviving Radiation}

\section{Nature of Some Unique Bacteria Surviving Substerilizing Irradiation}

During study of the highly radiation-resistant bacteria from chicken, a micrococcus that was beta hemolytic on blood agar was found (Welch and Maxcy 1979). In light of this implication that the isolate could be of public health significance, further observations for pathogenicity were made. Tests for hemolytic activity of extra cellular substances, leukocytic 
activity, presence of enzymes commonly associated with pathogenicity (coagulase, deoxyribonuclease, phosphatase), and pathogenicity for laboratory animals were all negative and therefore indicated that the organism would not be of public health significance. Other physiological characteristics were similar to the highly radiation-resistant micrococci isolated by other workers (Anderson et al. 1956; Davis et al. 1963; Lewis 1971).

These radiation-resistant vegetative cells also were uniquely resistant to drying. When cultures were placed on stainless steel and allowed to dry, there was little reduction in numbers during storage at room temperature for well over thirty months. The nature of the suspending medium in which these organisms were dried was of little influence. Thus, dried irradiated foods are likely to contain a few of these highly radiation-resistant vegetative cells.

Some other highly radiation-resistant bacteria, Moraxella-Acinetobacter, have another unique characteristic. Even though they are extremely resistant to drying, their water activity requirements for growth are greater than is found in ground beef (Snyder and Maxcy 1979). When the ground beef has water added, they grow well. This restraint on growth by low water activity was found to occur with chicken serum and increased concentrations of plate count broth. These observations have been corroborated by Eden and Rowley (personal communication).

In light of the extreme resistance of these bacteria to gamma radiation their survival of almost any proposed process of irradiation is to be expected. But, in a product with water activity equivalent to or less than that of ground beef, surviving organisms would not grow. Therefore, such products would be considered commercially sterile in the same sense that canned food products are now considered commercially sterile.

\section{Acquired Resistance}

Acquired resistance by mutation and/or adaptation through exposure of a culture of bacteria to a stressful force, e.g., heat, radiation, or sanitizer, is a generally recognized phenomenon (Erdman et al. 1961; Corry and Roberts 1970; Maxcy et al. 1971; Davies and Sinskey 1973). This process of acquiring resistance to radiation requires a carefully controlled sequence of growing pure cultures to near the maximum population density, irradiating to destroy nearly all the cells, and inoculating into a fresh medium for subsequent growth. The process of growth and irradiation is repeated a number of times, and the resulting culture may have con- 
siderably higher radiation resistance than the parent culture. The magnitude and limit of the increased resistance is dependent on the specific organism.

The nature of the process of acquiring resistance and the end effect on the cultures showed that the process was accompanied by a weakening of the cells in comparison to the parent culture (Maxcy 1977). The surviving irradiated cells of Salmonella typhimurium and Moraxella-Acinetobacter grew more slowly than the respective parent culture. The difference between parent and irradiated cells was accentuated by repetition of the process. In general, cultures with acquired resistance were more exacting in nutritional requirements, less tolerant to deviation from the optimum growth temperature, and less tolerant to reduced water activity.

An evaluation of the system of acquiring resistance and the end effects indicates the production of a resistant culture requires a highly specific set of laboratory conditions. The pure culture is not in competition with bacteria in the wild state where there would be a reversion to the common wild form through survival of the fittest. This set of highly theoretical conditions would not be expected in an industrial environment.

\section{Significance of Bacteria Surviving Radiation}

\section{Source of Highly Radiation-resistant Vegetative Cells}

Isolates of highly radiation-resistant vegetative cells have been found in diverse food environments (Anderson et al. 1956; Davis et al. 1963; Ito et al. 1972; Lewis 1971; Welch and Maxcy 1979). The source of the specific radiation-resistant bacteria isolated from beef is not known. Gulistani (1977) considered every logical point of entry. There was not a single source, but the greatest concentration was found on hair taken from the back of beef animals. In this habitat the most radiation-resistant isolates would not grow, because they require more moisture than is commonly on the hair. Their presence must be attributed to fortuitous contaminants from dust and their ability to withstand drying.

\section{Mutants as a Source of Residual Organisms in Foods}

There are two bodies of supporting evidence against the concept that the highly radiation-resistant cells arise as mutants. The first is that a parent culture is more vigorous than cells having been irradiated. Through 
the utilization of the characteristic of high resistance to drying, Sanders and Maxcy (1979) provided the second and more convincing argument in that highly radiation-resistant vegetative cells were isolated without their having been previously subjected to gamma radiation.

\section{Temperature Requirements for Growth of Radiation-resistant Bacteria}

Low temperature storage is the logically expected constraint that will limit many of the most radiation-resistant bacteria surviving substerilization (Welch and Maxcy 1975). However, enough of the common spoilage flora of pseudomonads and closely related species in beef survives a very low dose treatment to cause spoilage at $2{ }^{\circ} \mathrm{C}$ in 21 days (Maxcy and Tiwari 1973).

\section{Public Health Significance of the Surviving Flora}

\section{Outgrowth of the Surviving Flora from Substerilizing Irradiation}

Growth of bacteria in beef irradiated at a substerilizing level produces an obvious off odor. Consumer recognition of spoilage likewise would be obvious even though this criterion of public health protection is of spurious value. The process of change in dominant flora, spoilage by surviving flora, consumer recognition of spoilage, and public health protection is similar to pasteurization of milk. The public has benefitted from this process for nearly a century.

\section{Relative Resistance of Bacteria of Public Health Significance}

Those bacteria surviving substerilizing irradiation of most interest are those of direct public health significance. The extent of survivors depends on the dose level and the conditions of irradiation. Some examples of pathogens to be considered in setting dose levels and irradiation conditions are given as relative resistance expressed as $D_{10}$ values. Salmonellae in broth at ambient temperature have $\mathrm{D}_{10}$ values of 28-33 Krad (Maxcy and Rowley 1973). Yersinia enterocolitica has a $D_{10}$ value of approximately $20 \mathrm{Krad}$ in ground beef at $25^{\circ} \mathrm{C}$ (El-Zawahry and Rowley, 1977). Campylobacter fetus subsp. jejuni had a $\mathrm{D}_{10}$ value of $31 \mathrm{Krad}$ in broth at ambient temperature (J.D. Lambert, University of Nebraska, Lincoln. Unpublished). Thus it is apparent that a low dose of $200 \mathrm{Krad}$ would essentially eliminate these common bacteria of public health significance. 


\section{Conclusions}

Substerilizing irradiation of foods leaves a relatively diverse and often weakened flora depending on the dose level and conditions during irradiation. Furthermore, fate of these bacteria during post-irradiation storage is dependent on the nature of the food and storage conditions, e.g., available water and temperature. The residual flora would include few if any bacteria of public health significance, because the common contaminants are quite sensitive to radiation. Irradiation of food therefore has potential for public health protection through application to fresh foods that are not amenable to heat pasteurization.

\section{References}

Anderson, A. W., Nordan, H. C., Cain, R. F., Parrish, G., and Duggan, D. 1956. Studies on radio-resistant micrococcus. I. Isolation, morphology, cultural characteristics, and resistance to gamma radiation. Food Technol. 10, 575-578.

Bruns, M. A. and Maxcy, R. B. 1978. Effect of selected solutes on growth and recovery of a radiation-resistant Moraxella sp. J. Food Sci. 43, 1386-1389.

Bruns, M. A. and Maxcy, R. B. 1979. Effect of irradiation temperature and drying on survival of highly radiation-resistant bacteria in complex menstrua. J. Food Sci. 44, 1743-1746.

Corry, J. E. L. and Roberts, T. A. 1970. A note on the development of resistance to heat and gamma radiation in Salmonella. J. Appl. Bacteriol. 33, 733-737.

Davies, R. and Sinskey, A. J. 1973. Radiation-resistant mutants of Salmonella typhimurium LT2: Development and characterization. J. Bacteriol. 113, 133-144.

Davis, N. S., Silverman, G. J., and Masurovsky, E. B. 1963. Radiation-resistant, pigmented coccus isolated from haddock tissue. J. Bacteriol. 86, 294-298.

El-Zawahry, Y. A. and Rowley, D. B. 1979. Radiation resistance and injury of Yersinia enterocolitica. Appl. Environ. Microbiol. 37, 50-54.

Erdman, I. E., Thatcher, F. S., and Macqueen, K. F. 1961. Studies on the irradiation of microorganisms in relation to food preservation. II. Irradiation resistant mutants. Can. J. Microbiol. 7, 207-215.

Gulistani, A. W. 1977. The ecology and resistance of Moraxella-Acinetobacter. Ph.D. Thesis, University of Nebraska, Lincoln, Nebraska. 
Ito, H., Iizuka, H., Okazawa, Y., and Watanabe, H. 1972. Studies on the microorganisms of cereal grain. XIV. Radiosensitivity of a radioresistant strain of Pseudomonas radiora and its recovery from radiation damage. J. Agri. Chem. Soc. Japan. 46, 127-135.

Lewis, N. F. 1971. Studies on a radio-resistant coccus isolated from Bombay duck (Harpodon nehereus). J. Gen. Microbiol. 66, 29-35.

Ma, K. and Maxcy, R. B. 1981. Factors influencing radiation resistance of vegetative bacteria and spores associated with radappertization of meat. J. Food Sci. 46, 612-616.

Maxcy, R. B. 1977. Comparative viability of unirradiated and gamma irradiated bacterial cells. J. Food Sci. 42, 1056-1059.

Maxcy, R. B. and Rowley, D. B. 1978. Radiation-resistant vegetative bacteria in a proposed system of radappertization of meats, pp. 347-359. In Food Preservation by Irradiation, Vol. 1. International Atomic Energy Agency, Vienna.

Maxcy, R. B. and Tiwari, N. P. 1973. Irradiation of meats for public health protection. In Radiation Preservation of Food. International Atomic Energy Agency, Vienna.

Maxcy, R. B., Tiwari, N. P., and Soprey, P. R. 1971. Changes in Escherichia coli associated with acquired tolerance for quaternary ammonium compounds. Appl. Microbiol. 22, 229-232.

Sanders, S. W. and Maxcy, R. B. 1979. Isolation of radiation-resistant bacteria without exposure to irradiation. Appl. Environ. Microbiol. 38,436-439.

Snyder, L. D. and Maxcy, R. B. 1979. Effects of $A_{w}$ of meat products on growth of radiation resistant Moraxella-Acinetobacter. J. Food Sci. 44, 33-36.

Tan, S-T and Maxcy, R. B. 1982. Inactivation and injury of a hemolytic radiation-resistant micrococcus isolated from chicken meat. J. Food Sci. 4 7, 1345-1349,1353.

Welch, A. B. and Maxcy, R. B. 1975. Characterization of radiation-resistant vegetative bacteria in beef. Appl. Microbiol. 30, 242-250.

Welch, A. B. and Maxcy, R. B. 1979. Characteristics of some radiation-resistant hemolytic micrococci isolated from chicken. J. Food Sci. 44, 673-675. 